\title{
A Case of Intraductal Papillary Neoplasm of the Bile Duct with Stromal Invasion
}

\author{
Atsushi Nanashima ${ }^{a}$ Yorihisa Sumida ${ }^{a}$ \\ Kouichi Tomoshige $^{a}$ Hiroaki Takeshita $^{a}$ \\ Kenichirou Shibata ${ }^{a}$ Terumitsu Sawai $^{a}$ Toru Yasutake $^{a}$ \\ Naoe Kinoshita ${ }^{b}$ Tomayoshi Hayashi $^{b}$ Yasuni Nakanumac \\ Takeshi Nagayasu ${ }^{a}$

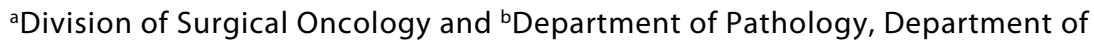 \\ Translational Medical Sciences, Nagasaki University Graduate School of \\ Biomedical Sciences, Nagasaki, and 'Department of Human Pathology, Kanazawa \\ University Graduate School of Medicine, Kanazawa, Japan
}

\section{Key Words}

Intraductal papillary neoplasm · Bile duct · Right hepatectomy · Superficial extension

\begin{abstract}
Intraductal papillary neoplasm of the bile duct (IPNB) represents biliary papillary tumors mainly growing and is considered to be of relatively low-grade malignancy. Here we report a case of IPNB in whom the poorly differentiated component deeply infiltrated the bile duct wall. A 77-year-old male had an invasive carcinoma of the bile duct $3 \mathrm{~cm}$ in size. He underwent right hemihepatectomy with combined resection of the extrahepatic bile duct. Papillary growing tumor was observed in the common bile duct and the right posterior Glisson's pedicle was invaded. Histologic finding showed papillary adenocarcinoma in the surface layer superficially extending to the epithelium of the surrounding bile duct. In the subserosal layer, the tumor represented poorly differentiated adenocarcinoma. The tumor was diagnosed as invasive bile duct carcinoma arising from IPNB.
\end{abstract}

\section{Introduction}

Intraluminal papillary tumors of extra- or intrahepatic bile ducts generally show highor low-grade dysplasia or are well-differentiated adenocarcinomas [1]. These types of tumors are not infrequently associated with superficial spread of carcinoma cells along the biliary mucosa without invasiveness [2]. Approximately $10 \%$ of hilar bile duct 
carcinomas are of the papillary type while approximately $15 \%$ of intrahepatic cholangiocarcinomas are of the intraductal growth type [3]. Biliary papillomatosis or papilloma are also sometimes included in this category of biliary tumors [4]. This type of biliary papillary tumor shows less invasiveness and more favorable outcome compared with other types of intrahepatic cholangiocarcinomas and not infrequently presents as multifocal papillary epithelial lesions in the bile duct with or without mucin production [5]. Chen et al. [6] and Nakanuma et al. [7] surveyed such cases in Taiwan and also in Japan, and they proposed the collective term of intraductal papillary neoplasm of the bile duct (IPNB) for such biliary papillary tumors. Interestingly, the clinicopathological features of IPNB resemble those of intraductal papillary mucin-producing neoplasia (IPMN) of the pancreas [8-10]. Although IPNB is considered to be of relatively low-grade malignancy $[8,11]$, the clinical spectrum and characteristics of IPNB itself including postsurgical prognosis have not been fully evaluated. In this report, we present a case of IPNB with subserosal invasion by the component of poorly differentiated carcinoma.

\section{Case Report}

Here we describe a case of IPNB in a 77-year-old male with liver dysfunction and diabetes. The patient had no history of liver diseases such as viral hepatitis or alcoholic liver disease. Increased alkaline phosphatase level was found during the follow-up of diabetes. When examining abdominal images, biliary tumor was observed and, therefore, the patient was referred to our institute. Laboratory data showed mild obstructive jaundice as $1.5 \mathrm{mg} / \mathrm{dl}$ of total bilirubin, $49 \mathrm{IU} / \mathrm{l}$ of alanine aminotransferase, and $663 \mathrm{IU} / \mathrm{l}$ of alkaline phosphatase. Indocyanine green retention rate at $15 \mathrm{~min}$ was increased with $27.4 \%$ (normal range $<10 \%$ ) and the liver uptake ratio by ${ }^{99 \mathrm{~m}} \mathrm{Tc}$-galactosyl human serum albumin liver scintigraphy was decreased with 0.88 (normal range $>0.9$ ), which indicated injured liver function by biliary obstruction. Serum level of CA19-9 was highly increased with $124 \mathrm{U} / \mathrm{ml}$ (normal range $<37 \mathrm{U} / \mathrm{ml}$ ). Computed tomography (CT) showed a tumor of the bile duct $3 \mathrm{~cm}$ in size extending to the hepatic hilum (fig. 1). The bile duct in the right lateral sector was obstructed by tumor invasion and the portal branch in the same sector was stenotic. We performed right hepatectomy and combined resection of the common hepatic and bile duct and a regional lymphadenectomy was added. Papillary growing soft tumor was observed in the upper and middle bile duct, and the right lateral Glisson's pedicle and the cystic duct were obstructed by the tumor invasion (fig. 2$)$. The tumor was $3.1 \times 1.6 \mathrm{~cm}$ in size. The hepatic duct in the right paramedian sector and the left hepatic duct were remarkably dilated without obstruction and the intraductal lumen showed normal appearance in the resected specimen. Histologic finding showed remarkably papillary adenocarcinoma in the layer of the intraluminal side (fig. $3 \mathrm{a})$, which was superficially extending $(2 \mathrm{~cm}$ from the main tumor) to the epithelium of the intrahepatic duct. In the subserosal layer, the tumor transformed to poorly differentiated adenocarcinoma which obstructed the bile ducts in the right lateral sector (fig. 3b). Slight perineural, lymphatic and venous infiltrations were observed; however, there was no lymph node metastasis. Immunohistochemical analysis showed positive expression of MUC1, MUC4 and MUC5AC,negative expression of MUC2 and p53 overexpression. By pathologic consultation, the tumor was diagnosed as an invasive bile duct carcinoma arising from IPNB, pacreatobiliary type.

\section{Discussion}

IPNB may evolve through a common pathological process and shares clinicopathological features with pancreatic cystic neoplasms such as IPMN [7]. Helical $\mathrm{CT}$ and MR imaging can identify dilation and cystic changes in biliary and pancreatic ducts in asymptomatic patients $[9,12]$, enabling diagnosis of malignancy at an earlier stage and providing reliable patient follow-up. Since the mechanism of carcinogenesis of pancreatic cystic neoplasms has been clarified by advances in histological and molecular diagnostic techniques, it is now clear that intraepithelial pancreatic neoplasia is the microscopic precursor lesion of pancreatic carcinoma, and IPMN or mucinous cystic neoplasm are macroscopic precursor lesions [9]. The diagnostic algorithm for pancreatic 
cystic tumors is designed to distinguish benign from malignant lesions $[9,13]$. In bile duct carcinomas, on the other hand, intraepithelial biliary neoplasia or IPNB are thought to be similar precursor lesions, and the molecular characteristics of carcinogenesis have been clarified as well $[14,15]$. IPNB seems to be a counterpart of IPMN [7]. However, in our experience, most IPNB contained carcinomatous lesions, even the small cystic lesions, and mucin production was observed in half of the cases (unpublished data), which was different from IPMN. Since the similarities and differences between IPNB and IPMN have not been fully clarified yet, the diagnostic or treatment algorithm for IPNB remains to be established at this stage. When IPNB is detected, most cases should be scheduled for surgical resection based on their malignant potential.

We have experienced 7 patients of IPNB including the present case [16]; 4 presented abdominal pain or discomfort due to biliary obstruction. However, another 3 patients had onset of liver dysfunction. There has been an increase in the number of reported cases of biliary neoplasms of the hepatobiliary system characterized by marked dilatation of the bile ducts or cystic biliary lesions with or without mucin secretion [17]. The number of patients who undergo surgical treatment for such lesions has also increased due to diagnostic and surgical improvements along with development of imaging modalities [18]. Advanced imaging modality can identify dilation and cystic changes in the biliary duct at an early stage in such cases. Yeh et al. reported the reliable classification of cholangiographic types according to the histopathological types of IPNB [8]. According to this imaging classification, the cholangiographic pattern of the present case was type IIIA (intrahepatic polypoid or cystic neoplasia with operable concomitant malignancy), in which the prevalence of microinvasive adenocarcinoma and papillary adenocarcinoma with stromal invasion wase dominant by Yeh's classification [8]. The present case showed a papillary adenocarcinoma with stromal invasion. Therefore, their morphological classification using an image diagnostic tool may be reliable to identify malignancy of IPNB. The onset of finding in the present case was elevated alkaline phosphatase level, which might be reliable to find development of biliary carcinoma [19].

The previous report recommended hemihepatectomy or extended hemihepatectomy for cases with extending tumor or diffusely dilated bile ducts [20]. In the present case, we also selected right hepatectomy for complete curable resection because the tumor seemed to extend to the confluent of hepatic duct in the right paramedian sector by CT and superficial spreading of the tumor along the biliary epithelium is also a characteristic feature of IPNB [1]. In the present case, $2 \mathrm{~cm}$ of superficial extension along the epithelium to the hepatic duct was observed as expected. It is important to decide on major hepatic resection in such cases because of diffuse dilatation of the bile duct extending in a segment or lobe and multifocal carcinogenesis [21]. The present case showed stromal invasion to the subserosal layer. Yeh et al. reported that 59 of 124 IPNB patients had invasive carcinoma [8]. Papillary growing biliary carcinomas might show lower potential of malignancy [8]. However, in the present case, the infiltrative portion showed poorly differentiated adenocarcinoma and, therefore, it is necessary to consider the malignant potential even in IPNB with papillary growth. Since similarity between IPMN and IPNB has been considered [7] and prognosis of patients with invasive IPMN is very poor, similar to those with pancreatic ductal adenocarcinoma [22], patients with invasive IPNB should be carefully monitored and considered to have similar prognosis to those with cholangiocellular carcinoma. Zen et al. examined mucinous expression of IPNB [14]. The expression of MUC1, MUC2, or MUC5A might correlate with malignant transformation from IPNB to invasive or mucinous carcinoma of the bile duct. In our case, the expression of MUC2 and p53 was negative, and this finding might be according to the previous report $[23,24]$. Further studies of cellular characteristics such as protein expression or 


\begin{tabular}{r|l|l|l} 
Case Reports $/ \mathrm{h}$ & $\begin{array}{l}\text { Case Rep Gastroenterol 2008;2:314-320 } \\
\text { D0I: 10.1159/000154818 }\end{array}$ & Published online: September 30, 2008 & $\begin{array}{l}\text { O 2008 S. Karger AG, Basel } \\
\text { ISSN 1662-0631 } \\
\text { www.karger.com/crg }\end{array}$ \\
\hline
\end{tabular}

genetic alterations will be necessary to clarify the pathogenesis of IPNB. IPNB or intraductal papillary growth type of intrahepatic cholangiocarcinoma is a good indication for surgical resection, and complete resection is associated with better prognosis compared with other cholangiocarcinomas [25]. In the present case, lymph node metastasis was not observed despite deep invasion with the microscopic infiltration of cancer cells in the surrounding tissues. The recent report by Yeh et al. revealed poor prognosis in patients with lymph node metastasis (the 5-year survival rate was 14\%) [8]. Furthermore, the negative surgical margin could be obtained by the extended hepatic resection. Good prognosis after operation could be expected by these reasons in the present case. To accomplish good prognosis after treatment for IPNB, diagnosis at the earliest stage followed by curative resection is necessary.

In conclusion, we report the clinicopathological findings in a case of IPNB with stromal invasion who underwent surgical resection. The malignant potential of IPNB is usually lower than that of other bile duct carcinomas; however, it is noted that invasive transformation might sometimes occur even in IPNB. Surgical complete resection is a better therapeutic choice for IPNB to obtain the good prognosis.

Fig. 1. a CT showed a tumor (arrow) in the common bile duct extending to the hepatic hilum. $\mathbf{b}$ The bile duct in the right lateral sector was obstructed by the tumor and this lesion became atrophic.
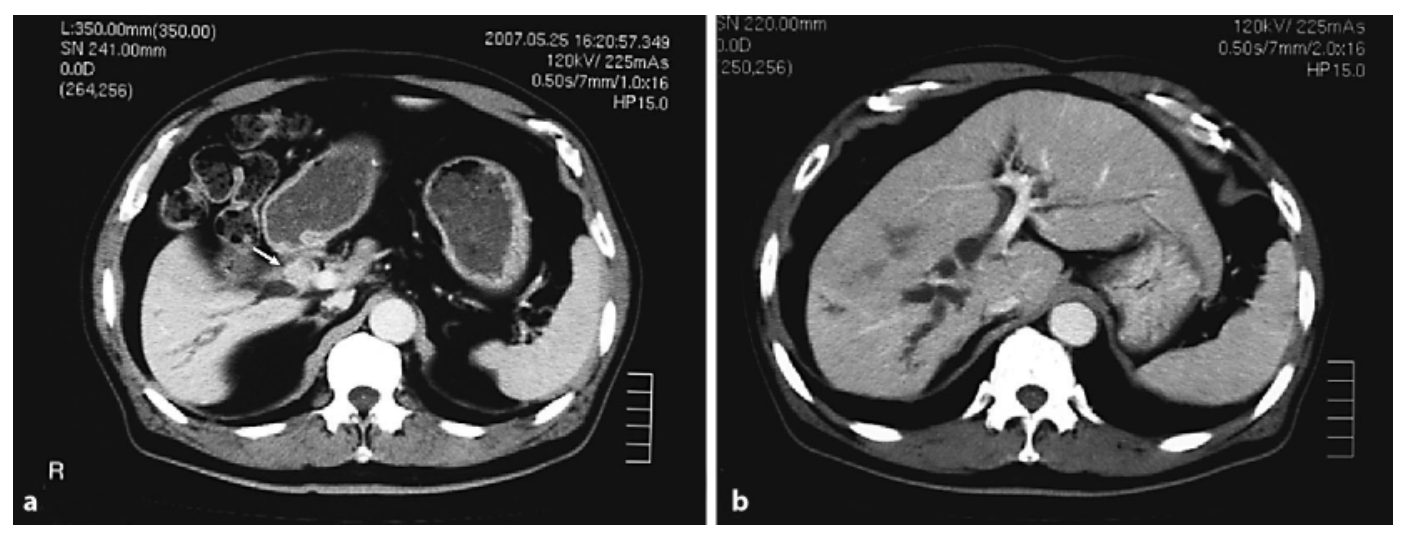


\begin{tabular}{r|l|l|l} 
Case Reports $/$ h & $\begin{array}{l}\text { Case Rep Gastroenterol 2008;2:314-320 } \\
\text { D01: 10.1159/000154818 }\end{array}$ & Published online: September 30, 2008 & $\begin{array}{l}\text { O 2008 S. Karger AG, Basel } \\
\text { ISSN 1662-0631 } \\
\text { www.karger.com/crg }\end{array}$ \\
\hline
\end{tabular}

Fig. 2. A papillary growing soft tumor was observed in the lumen of bile duct, and the right lateral Glisson's pedicle and the cystic duct were obstructed by the tumor invasion.

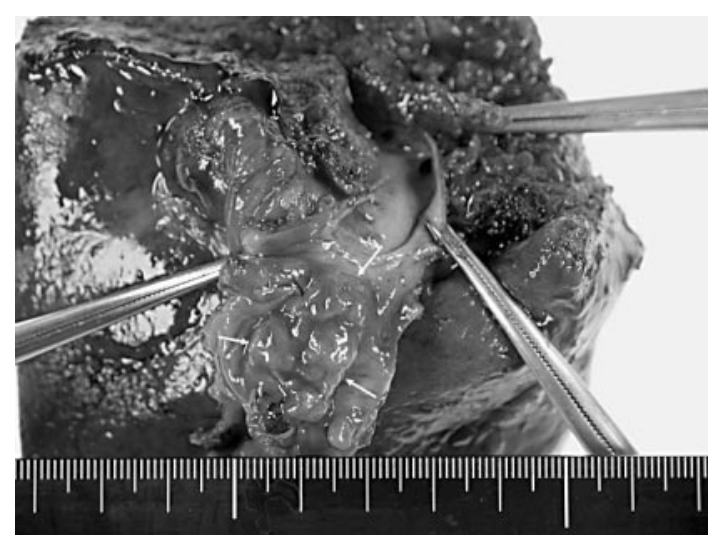

Fig. 3. a The papillary adenocarcinoma in the layer of the intraluminal side was identified as IPNB, which was superficially extending to the epithelium of the intrahepatic duct. $\mathbf{b}$ In the subserosal layer, the tumor was changed to poorly differentiated adenocarcinoma, which obstructed the bile ducts in the right lateral sector.

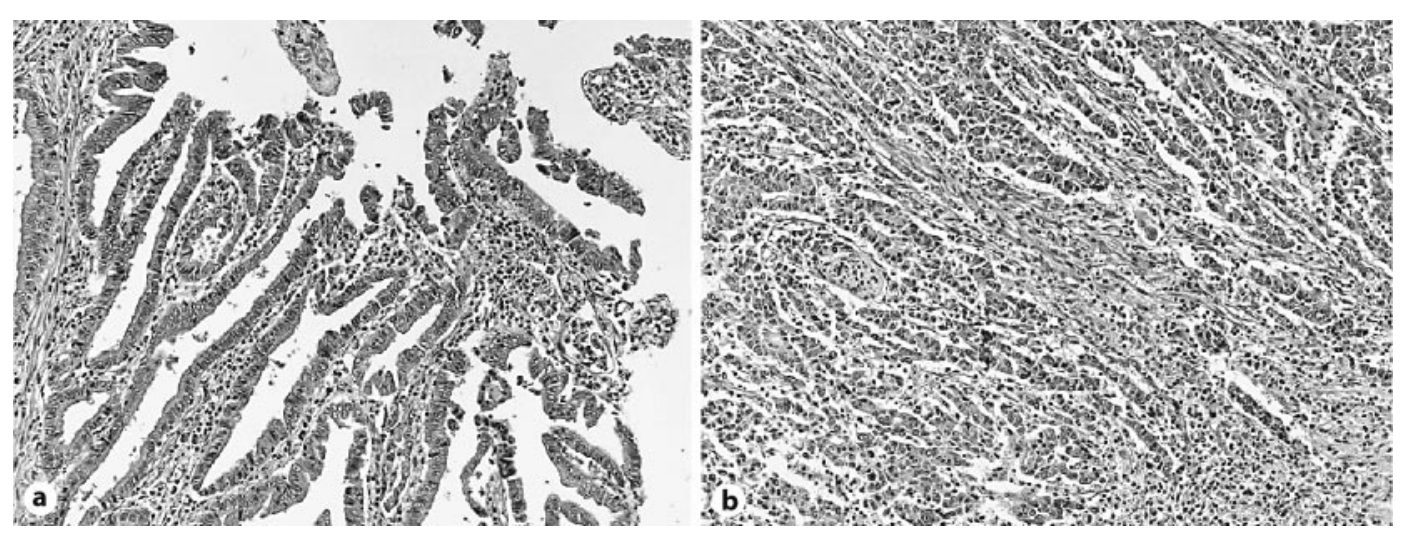




\section{References}

1 Okamoto A, Tsuruta K, Matsumoto G, Takahashi T, Kamisawa T, Egawa N, Funata N: Papillary carcinoma of the extrahepatic bile duct: characteristic features and implications in surgical treatment. J Am Coll Surg 2003;196:394-401.

2 Chamberlain RS, Blumgart LH: Hilar cholangiocarcinoma: A review and commentary. Ann Surg Oncol 2000;7:55-66.

-3 Sano T, Kamiya J, Nagino M, Uesaka K, Kondo S, Kanai M, Hayakawa N, Nimura Y: Macroscopic classification and preoperative diagnosis of intrahepatic cholangiocarcinoma in Japan. J Hepatobiliary Pancreat Surg 1999;6:101-107.

-4 Lee SS, Kim MH, Lee SK, Jang SJ, Song MH, Kim KP, Kim HJ, Seo DW, Song DE, Yu E, Lee SG, Min YI: Clinicopathologic review of 58 patients with biliary papillomatosis. Cancer 2004;100:783-793.

5 Sudo Y, Harada K, Tsuneyama K, Katayanagi K, Zen Y, Nakanuma Y: Oncocytic biliary cystadenocarcinoma is a form of intraductal oncocytic papillary neoplasm of the liver. Mod Pathol 2001;14:1304-1309.

-6 Chen TC, Nakanuma Y, Zen Y, Chen MF, Jan YY, Yeh TS, Chiu CT, Kuo TT, Kamiya J, Oda K, Hamaguchi M, Ohno Y, Hsieh LL, Nimura Y: Intraductal papillary neoplasia of the liver associated with hepatolithiasis. Hepatology 2001;34:651-658.

7 Nakanuma Y, Sasaki M, Ishikawa A, Tsui W, Chen TC, Huang SF: Biliary papillary neoplasm of the liver. Histol Histopathol 2002;17:851-861.

${ }_{8}$ Yeh TS, Tseng JH, Chiu CT, Liu NJ, Chen TC, Jan YY, Chen MF: Cholangiographic spectrum of intraductal papillary mucinous neoplasm of the bile ducts. Ann Surg 2006;244:248-253.

-9 Singh M, Maitra A: Precursor lesions of pancreatic cancer: molecular pathology and clinical implications. Pancreatology 2007;7:9-19.

10 Klöppel G, Kosmahl M: Cystic lesions and neoplasms of the pancreas. The features are becoming clearer. Pancreatology 2001;1:648-655.

-11 Helling TS, Strobach RS: The surgical challenge of papillary neoplasia of the biliary tract. Liver Transplant Surg 1996;2:290-298.

$\checkmark 12$ Lim JH, Kim YI, Park CK: Intraductal mucosal-spreading mucin-producing peripheral cholangiocarcinoma of the liver. Abdom Imaging 2000;25:89-92.

13 Garcea G, Ong SL, Rajesh A, Neal CP, Pollard CA, Berry DP, Dennison AR: Cystic lesions of the pancreas. A diagnostic and management dilemma. Pancreatology 2008;8:236-251.

- 14 Zen Y, Adsay NV, Bardadin K, Colombari R, Ferrell L, Haga H, Hong SM, Hytiroglou P, Klöppel G, Lauwers GY, van Leeuwen DJ, Notohara K, Oshima K, Quaglia A, Sasaki M, Sessa F, Suriawinata A, Tsui W, Atomi Y, Nakanuma Y: Biliary intraepithelial neoplasia: an international interobserver agreement study and proposal for diagnostic criteria. Mod Pathol 2007;20:701-709.

-15 Itatsu K, Zen Y, Ohira S, Ishikawa A, Sato Y, Harada K, Ikeda H, Sasaki M, Nimura Y, Nakanuma Y: Immunohistochemical analysis of the progression of flat and papillary preneoplastic lesions in intrahepatic cholangiocarcinogenesis in hepatolithiasis. Liver Int 2007;27:1174-1184.

16 Nanashima A, Sumida Y, Tamaru N, Nakanuma Y, Abo T, Tanaka K, Sawai T, Yasutake T, Nagayasu T, Hayashi T, Fukuda Y: Intraductal papillary neoplasm of the bile duct extending superficially from the intrahepatic to extrahepatic bile duct. J Gastroenterol 2006;41:495-499.

-17 Yoon KH, Ha HK, Kim CG, Roh BS, Yun KJ, Chae KM, Lim JH, Auh YH: Malignant papillary neoplasms of the intrahepatic bile ducts: CT and histopathologic features. AJR Am J Roentgenol 2000;175:1135-1139.

- 18 Yeh CN, Jan YY, Yeh TS, Hwang TL, Chen MF: Hepatic resection of the intraductal papillary type of peripheral cholangiocarcinoma. Ann Surg Oncol 2004;11:606-611.

19 Wilson JW, Kronborg IJ, Roberts-Thomson IC: High serum levels of alkaline phosphatase are associated with cancer in cholestatic jaundice. Aust N Z J Surg 1985;55:453-454.

20 Jarnagin WR, Bowne W, Klimstra DS, Ben-Porat L, Roggin K, Cymes K, Fong Y, DeMatteo RP, D’Angelica M, Koea J, Blumgart LH: Papillary phenotype confers improved survival after resection of hilar cholangiocarcinoma. Ann Surg 2005;241:703-712. 
21 Abraham SC, Lee JH, Hruban RH, Argani P, Furth EE, Wu TT: Molecular and immunohistochemical analysis of intraductal papillary neoplasms of the biliary tract. Hum Pathol 2003;34:902-910.

22 Woo SM, Ryu JK, Lee SH, Yoo JW, Park JK, Kim YT, Yoon YB: Survival and prognosis of invasive intraductal papillary mucinous neoplasms of the pancreas: comparison with pancreatic ductal adenocarcinoma. Pancreas 2008;36:50-55.

23 Amaya S, Sasaki M, Watanabe Y, Tsui WM, Tsuneyama K, Harada K, Nakanuma Y: Expression of MUC1 and MUC2 and carbohydrate antigen Tn change during malignant transformation of biliary papillomatosis. Histopathology 2001;38:550560 .

24 Teh M, Wee A, Raju GC: An immunohistochemical study of p53 protein in gallbladder and extrahepatic bile duct/ampullary carcinomas. Cancer 1994;74:1542-1545.

25 Nagakawa T, Kayahara M, Ikeda S, Futakawa S, Kakita A, Kawarada H, Matsuno M, Takada T, Takasaki K, Tanimura H, Tashiro S, Yamaoka Y: Biliary tract cancer treatment: results from the Biliary Tract Cancer Statistics Registry in Japan. J Hepatobiliary Pancreat Surg 2002;9:569-575. 